\title{
Using computers to identify non-compliant people at increased risk of osteoporotic fractures in general practice: a cross-sectional study
}

\author{
S. de Lusignan $\cdot$ J. van Vlymen $\cdot$ N. Hague $\cdot$ N. Dhoul
}

Received: 13 January 2006 / Accepted: 13 June 2006 / Published online: 24 August 2006

(C) International Osteoporosis Foundation and National Osteoporosis Foundation 2006

\begin{abstract}
Background National guidelines recommend bisphosphonates for secondary prevention of osteoporotic fractures; however, poor compliance may result in sub-optimal prevention.

Objective This study reports the feasibility of using GP electronic records to identify poorly compliant post-menopausal women who may be at increased risk of fragility fractures.

Design Cross-sectional study of general practice computer records.

Subjects Women over 45 years, registered in 29 practices across England with a total population of approximately 200,000 .

Methods MIQUEST (Morbidity Information Query and Export Syntax) a data extraction application was used to extract prescription, diagnostic data and probable fragility fractures (hip, vertebral, wrist). All women $>45$ years who received a first prescription for a weekly bisphosphonate (alendronate or risedronate) at least a year before data extraction were identified. Each record was examined to determine the number of days of prescribed treatment.

Results Of 97992 registered women, 44\% (42734) were $>45$ years. Prevalence of likely fragility fractures in women over 45 was 5.1\% (2195/42734). 3.0\% (1286/42734, mean age 72 years) received a prescription for a bisphosphonate in the 360 day period prior to data extraction with a median duration of treatment of 267 days. $45 \%$ (584/1286) received prescriptions covering $>288 / 360$ days (Medicine Possession Ratio $>80 \%)$; $13 \%(161 / 1286)$ collected prescriptions covering $>360$ days. In those prescribed bisphosphonates, $23 \%(294 / 1286)$ had a likely fragility fracture.
\end{abstract}

S. de Lusignan $(\varangle) \cdot J$. van Vlymen $\cdot N$. Hague $\cdot N$. Dhoul Community Health Sciences, St. George's University of London,

London, UK

e-mail: slusigna@sgul.ac.uk
Conclusions Women $>45$ years with probable fragility fractures are more likely to be prescribed bisphosphonates, though less than half will be actually taking them as prescribed. GPs should use computer technology to identify poorly compliant patients who are unnecessarily at risk of fracture.

Keywords Biphosphonates · Computerised · Fractures · Medical records systems · Osteoporosis · Patient compliance $\cdot$ Postmenopausal $\cdot$ Spontaneous $\cdot$ Treatment refusal

Key Points

- Recorded prevalence of likely fragility fracture in women $>45$ years is $5.1 \%$

- Women $>45$ years with a likely fragility fracture are more likely to be prescribed a bisphosphonate.

- Less than half of women $>45$ years $(45 \%)$ prescribed a bisphosphonate have collected a complete set of bisphosphonate prescriptions for their last year of therapy and the rate was not significantly different $(42 \%)$ in women $>45 \mathrm{yrs}$ with a likely fragility fracture.

- About 1 in $8(13 \%)$ are collecting an excess number of prescriptions.

- Computer searches would allow women who are likely under and over-users of bisphosphonates to be identified. A starting point might be those with existing likely fragility fractures.

\section{Introduction}

Bisphosphonates reduce the fracture risk in postmenopausal women with osteoporosis; however, compliance to therapy 
is poor, putting patients at risk. Bisphosphonates are known to increase bone mineral density (BMD) in the lumbar spine and hip and this appears to be clinically significant, in that new vertebral fractures, non-vertebral fractures and hip fracture rates are all reduced [1-4]. However, compliance with bisphosphonates is known to be poor $[5,6]$. Further, poor compliance translates into reduced bone mineral density (BMD) [7] increased hospitalisation and fracture rates $[8,9]$. Compliance can be quantified using the medicines possession ratio (MPR); the ratio of the number of days' supply to the length of the study period. For bisphosphonates an MPR under $80 \%$ is associated with increased fracture risk $[8,10]$.

The UK national guidelines recommend the use of bisphosphonates for the secondary prevention of fragility fractures in women with osteoporosis [11]. The guidance recommends the use of bisphosphonates in women 75 years and over, who have had a fracture without the need for measurement of BMD for those between 65 and 74 after measurement of BMD and in younger women if they have additional risk factors. In theory these patients should be easy to find from general practice computer records. Although computerisation is ubiquitous in UK general practice, osteoporosis data recording is variable [12]. Repeat prescribing data are generally complete and reliable [13]. However, in osteoporosis, diagnostic data are poor and there are technical problems which prevent the easy recording of dual X-ray densitometry (DXA) scan results [14].

We carried out this study to investigate the feasibility of using routinely collected computer data to improve the quality of care for people with osteoporosis and help practices implement the new national guidelines. We decided to test the feasibility of identifying women who do not persist with bisphosphonate therapy, especially those with a likely fragility fracture or a pre-existing computer diagnosis of osteoporosis.

\section{Method}

We recruited a sample from practices who had participated previously in PCDQ (Primary Care Data Quality) programmes $[15,16]$. We excluded practices who had been involved in previous PCDQ osteoporosis studies $[12,17]$ as this may have improved their osteoporosis computer data quality and we wanted our sample to be as representative as possible of "usual" UK practice. We invited practices from the north east and north west of England, London and the south east. We collected these data between March and May 2005.

We defined the dataset needed to answer our research question. The elements of the dataset were: demographic details, fracture recording, use of therapy to treat or prevent osteoporosis and the last twelve bisphosphonate prescriptions.

We used an established methodology to extract, aggregate, process, clean and analyse these data $[18,19]$. We use MIQUEST (Morbidity Information and Export Syntax), a Department of Health sponsored data extraction application to extract anonymous data from general practice computer systems [20].

We analysed the age-sex distribution of the population and compared it to the 2001 census population so that we could standardise prevalence rates. We analysed in detail data for women $>45$ years, in line with other investigators methods [21, 22].

We looked at the types and age-distribution of fracture recording. We made the assumption that all fractures of wrist, hip and spine occurring over age 45 years were likely to be fragility fractures. We also included codes for fragility fracture. We separately searched the different sections of the clinical coding hierarchy (the UK uses Read codes) to identify the relevant events.

We identified the types of therapy prescribed for osteoporosis, including hormone replacement therapy; though recognising that the latter has a wide range of other indications. We included prescription data for any bisphosphonates with a licence for the treatment of osteoporosis. For technical reasons our extraction included pamidronate, ibandronate, clodronate and zoledronate, because these are included in the bisphosphonate coding hierarchy. These drugs are indicated for treatment of the pain from bone secondary cancer, they were excluded from our results. However, one of these, ibandronate, was in the process of obtaining a product licence for the treatment of osteoporosis. As none of the small number of patients on ibandronate had been prescribed over a year's therapy they were excluded from our results.

Finally, we examined the compliance with weekly bisphosphonates, alendronate and risedronate, over a oneyear period. We did this by analysing the last 12 prescriptions issued. Our previous studies indicated that these medications were never prescribed for less than one month and usually for two to six months at a time $[12,17]$. We therefore felt that collecting data about the last 12 prescriptions would ensure we had data for at least a year. We set a cut off that all of these 12 prescriptions must have been issued more than 180 days (six months) before the data were extracted, so we would most likely capture fracture data recorded later when hospital discharge information came through.

We used the SPSS (Statistical Package for Social Sciences) to measure the number of days of therapy prescribed in the latest year of therapy. All the quantity elements were converted into the number of days of therapy. We did this by 
converting one "original pack" into the pack size defined in the British National Formulary and converting this into day therapy. The SPSS vector command was used to reorder the triplet of information we held about each prescription (drug code, date and quantity). The days prescribed for each patient for the time period between 18 months before (420 days) and six months (180 days) before data collection were then calculated.

We then calculated the percentage of people who complied for 12 months the median duration of therapy of those who did not persist for 12 months and the percentage of patients with a medicine possession ratio (MPR) of less than $80 \%$ (i.e., they collected prescriptions for less than $80 \%$ of a year: $<288$ days). To see if there was any relationship between compliance and a previous fragility fracture, we subsequently looked at the categories of compliance. Compliance of $<50 \%$ is described as poor, 50-79\% medium, 80-90\% good, $>90 \%$ excellent.

Finally, we looked to see whether a greater or lesser proportion of women $>45$ years with likely fragility fractures were persisting with their bisphosphonate therapy and whether people with multiple fractures were more likely to be compliant.

Statistical methods Mean is used to describe normally distributed variables, median and interquartile ranges (IQR) to describe variables which are not normally distributed. Chi-square $\left(\mathrm{X}^{2}\right)$ tests were performed to determine whether any changes in proportion were statistically significant.

Ethics Central ethics approval was granted for this study.

\section{Results}

Our sample had an age-sex profile close to the national average. The combined population from 29 practices was
195,910. The practices range in size from 1,817 to 13,693 (mean list size 6,756, median 7,127, IQR 2,325). Osteoporosis diagnosis recording rate was $1.08 \%(n=2,107)$, with a male-female recording ratio of $1: 8$ (males $n=230$; females $\mathrm{n}=1,877$ ).

In women over 45 years old $(n=42,734)$, the recorded prevalence was $4.31 \%(n=1,843)$. The standardised recorded prevalence of a diagnosis of osteoporosis using the 2001 census was $1.03 \%$. The recorded prevalence of osteoporosis was variable between practices the prevalence varied from $0.00 \%$ to $2.50 \%$, (median $0.93 \%$ IQR $0.74 \%$ ).

The recorded prevalence of fractures increased with age. In males it was higher in younger men, but the converse applied in older women. The recording of fractures in males under 45 years had a higher fracture rate than females $(\mathrm{M}$ $<45$ yrs $1.67 \%$; F < 45 yrs $1.05 \%$ ), but in women over 45 years old the prevalence of fractures is much greater $(\mathrm{M}$ $\geq 45$ yrs $3.39 \% ; \mathrm{F} \geq 45$ yrs $5.90 \%$ ), these differences in proportion are statistically significant (Chi-square test $\mathrm{p}<0.001)$. The difference in fracture rates gets larger with increasing age (Table 1).

A wide range of therapies for osteoporosis are used in the study practices and the numbers prescribed treatment greatly exceed the numbers with a diagnosis of osteoporosis $(n=2,107)$. Therapies used include hormone replacement therapy (HRT; $n=9,865)$, calcium and vitamin D $(n=4,771)$, bisphosphonates $(n=2,977)$, selective estrogen receptor modulators (SERM; $n=252)$ and calcitonin $(n=20)$. The female to male ratio of drug therapy was 13:1 (Female 16614, Male 1271) (Table 2).

The weekly formulations of the bisphosphonates, alendronate and risedronate account for the majority of current therapy. We found that about half as many patients had been on daily formulations of bisphosphonates, compared with the weekly formulations (daily $n=907$, weekly $n=2,064)$. However, a small proportion of the people persisted in taking a daily bisphosphonate, $11.26 \%$ (262/ 2326), at the end of the study.

Table 1 Age-sex profile of fracture recording

\begin{tabular}{|c|c|c|c|c|c|c|}
\hline \multirow[b]{2}{*}{ Age } & \multicolumn{3}{|l|}{ Male } & \multicolumn{3}{|l|}{ Female } \\
\hline & $\mathrm{n}$ & Fracture recording & Fracture prevalence & $\mathrm{n}$ & Fracture recording & Fracture prevalence \\
\hline $0-29$ & 34881 & 447 & $1.28 \%$ & 33065 & 296 & $0.90 \%$ \\
\hline $30-39$ & 15198 & 331 & $2.18 \%$ & 14480 & 178 & $1.23 \%$ \\
\hline $40-49$ & 15709 & 384 & $2.44 \%$ & 14585 & 232 & $1.59 \%$ \\
\hline $50-59$ & 12586 & 374 & $2.97 \%$ & 12471 & 247 & $1.98 \%$ \\
\hline $60-69$ & 9789 & 325 & $3.32 \%$ & 9949 & 471 & $4.73 \%$ \\
\hline $70-79$ & 6636 & 269 & $4.05 \%$ & 7574 & 719 & $9.49 \%$ \\
\hline $80-89$ & 2726 & 150 & $5.50 \%$ & 4627 & 702 & $15.17 \%$ \\
\hline $90+$ & 393 & 31 & $7.89 \%$ & 1241 & 257 & $20.71 \%$ \\
\hline Total & 97918 & 2311 & $2.36 \%$ & 97992 & 3102 & $3.17 \%$ \\
\hline
\end{tabular}


Table 2 Age-sex profile of the use of osteoporosis therapies

\begin{tabular}{|c|c|c|c|c|c|}
\hline Male & $\begin{array}{l}\text { Hormone replacement } \\
\text { therapy }\end{array}$ & Calcium and Vitamin D & Bisphosphonate & $\begin{array}{l}\text { Selective estrogen receptor } \\
\text { modulator }\end{array}$ & Calcitonin \\
\hline Age bands & $\mathrm{n}$ & $\mathrm{n}$ & $\mathrm{n}$ & $\mathrm{n}$ & $\mathrm{n}$ \\
\hline $0-29$ & 5 & 81 & 7 & 0 & 0 \\
\hline $30-39$ & 3 & 41 & 11 & 1 & 0 \\
\hline $40-49$ & 5 & 47 & 21 & 0 & 0 \\
\hline $50-59$ & 6 & 83 & 47 & 0 & 1 \\
\hline $60-69$ & 4 & 157 & 111 & 0 & 1 \\
\hline $70-79$ & 3 & 218 & 130 & 0 & 2 \\
\hline $80-89$ & 2 & 155 & 82 & 0 & 1 \\
\hline $90+$ & 0 & 30 & 16 & 0 & 0 \\
\hline Total & 28 & 812 & 425 & 1 & 5 \\
\hline Female & $\begin{array}{l}\text { Hormone replacement } \\
\text { therapy }\end{array}$ & Calcium and Vitamin D & Bisphosphonate & $\begin{array}{l}\text { Selective estrogen receptor } \\
\text { modulator }\end{array}$ & Calcitonin \\
\hline Age bands & $\mathrm{n}$ & $\mathrm{n}$ & $\mathrm{n}$ & $\mathrm{n}$ & $\mathrm{n}$ \\
\hline $0-29$ & 60 & 102 & 5 & 0 & 0 \\
\hline $30-39$ & 168 & 130 & 15 & 0 & 0 \\
\hline $40-49$ & 990 & 256 & 70 & 8 & 0 \\
\hline $50-59$ & 4010 & 499 & 299 & 55 & 0 \\
\hline $60-69$ & 3413 & 766 & 595 & 85 & 3 \\
\hline $70-79$ & 999 & 1016 & 814 & 79 & 4 \\
\hline $80-89$ & 180 & 908 & 634 & 24 & 6 \\
\hline $90+$ & 17 & 282 & 120 & 0 & 2 \\
\hline Total & 9837 & 3959 & 2552 & 251 & 15 \\
\hline
\end{tabular}

Bisphosphonates which at the time of the study were not indicated for use in osteoporosis (clodronate, pamidronate, ibandronate, tiludronate and andzoedronate) accounted for less than $1 \%$ of prescriptions for bisphosphonates.

$3.0 \%$ (1286/42734, mean age 72 years, IQR 17 years) received a prescription for a weekly bisphosphonate in the 360-day period prior to data extraction with a mean duration of treatment 231 days, median duration of treatment, 267 days, 25\%tile 112 days, 75\%tile 336 days, IQR 224 days). In females over 45 years $(n=42,734)$ approximately three times as many were taking weekly alendronate $(\mathrm{n}=1,297 ; 3.0 \%)$ compared with risedronate $(\mathrm{n}=458 ; 1.1 \%)$.

1,286 patients had 12 or more prescriptions for (alendronate 959 , risedronate 327 ; ratio $2.93: 1$ ). For these 1,286 individuals we could calculate a medicines possession ratio (MPR). We found that 45\% $(584 / 1,286)$ had an MPR $\geq 80 \%$ who we labelled "compliant". A slightly higher proportion of those taking alendronate $(47.0 \%, 451 / 959)$ were compliant compared with risedronate $(40.7 \%, 133 / 327)$; these differences are of borderline significance (Pearson Chisquare: $p=0.046$.) We also noted that some women collected too many prescriptions. $27.6 \%$ (161/584) collected excess prescriptions and that 3.6\% (21/584) had an MPR of over $120 \%$.
The level of compliance was not evenly spread across the four categories of compliance. Most women either had excellent compliance (MPR $>90 \%$ ) or poor compliance (MPR $<50 \%$ ), with relatively few in the medium (MPR 50$79 \%$ ) or good (MPR 80-90\%) category (Fig. 1). We found a similar pattern in men (data not shown).

Females over 45 years with a recording of a fracture are no more likely to be compliant with their weekly bisphosphonate therapy (alendronate or risedronate) than those without a fracture. $23 \%(294 / 1,286)$ of compliant people have had fracture; the compliant group have a fracture rate of $21 \%(123 / 584)$ compared with $24 \%$ (171/ $702)$ in the non-compliant group. These proportions are not significantly different (Pearson Chi-square $=0.16$ ). Multiple fractures were also not associated with improved compliance with bisphosphonates, it appears that women were generally poor or excellent in complying with therapy with relatively few in the intermediate groups (Fig. 1).

A fracture was found to be recorded in 27\% (183/684) of the people with a diagnosis of osteoporosis who were also prescribed a weekly bisphosphonate. Those with a diagnosis of osteoporosis are much more likely to have fracture than those who have not (27\% compared with 19\%) and this difference in proportion is statistically significant (Chisquare $\mathrm{p}<0.001)$. 
Based on these results a practice of 10,000 list size looking to implement national guidance on osteoporosis would expect to find:

- 37 post menopausal women who are not compliant to therapy (MPR $<80 \%$ ) and one post menopausal women using too much medication.

- Nine women over 45 with a fracture who are not compliant to bisphosphonates; three of whom would be aged 65 to 74 and five 75 years or older.

- Computer searches also identified 96 women over 45 with fractures not taking bisphosphonates of who 22 are 65 to 74 and 46 are 75 and older.

- 24 of the women over 45 who have a fracture and are not taking a bisphosphonate have a computer diagnosis of osteoporosis, six of these are 65 to 74 and 14 are 75 and over.

\section{Discussion}

\section{Principal findings}

There is scope to improve the general practice management of osteoporosis by identifying non-compliant patients using computer searches. Many patients' quality of care falls outside national guidelines. Less than half of women prescribed bisphosphonates collect sufficient prescriptions to be compliant with their therapy. We also noted that a proportion collect too many prescriptions. People who have had a fracture recorded are no more likely to be compliant with their therapy than those without a fracture and multiple fractures make patients no more likely to comply. Computer data has the potential to identify people with osteoporosis who are not compliant to therapy. The numbers of people identified by such searches are probably manageable within general practice.

Implications for practice

Practices could use computer searches to identify their noncompliant patients and those who are apparently collecting too many scripts. Additional input may lead to improvement in compliance to therapy. This might take the form of a telephone consultation, a nurse visit, or a review by a pharmacist as part of a medicines management programme or a consultation with their general practitioner. This approach could also be used as a method to implement national guidance on the secondary prevention of fractures in osteoporosis [11]. Practices with poor data quality should improve their diagnostic recording and see that fractures are coded and entered into the computer record.

Limitations of the study

Osteoporosis diagnostic data remains incomplete and it is likely that fracture recording remains an under-estimate of true prevalence. Our assumptions that women over 45 years are "postmenopausal" and fractures in older women are likely to be osteoporotic are inevitably oversimplifications. Sanders et al. found that only $71 \%$ and $80 \%$ of pelvic and hip fractures, respectively, were truly osteoporotic [23]. The study was also limited by our ability to only extract structured data and the confused way that fractures and any DXA scan results are stored within the clinical record. We only looked at the structured or "coded" data in the clinical computer record. We did not extract free text or check any paper notes, hospital letters or reports. The clinical coding system has limitations: no codes for "fragility fracture" exist and it is impossible in the most used clinical computer system to
Fig. 1 Category of compliance with a weekly bisphosphonate and likelihood of fracture

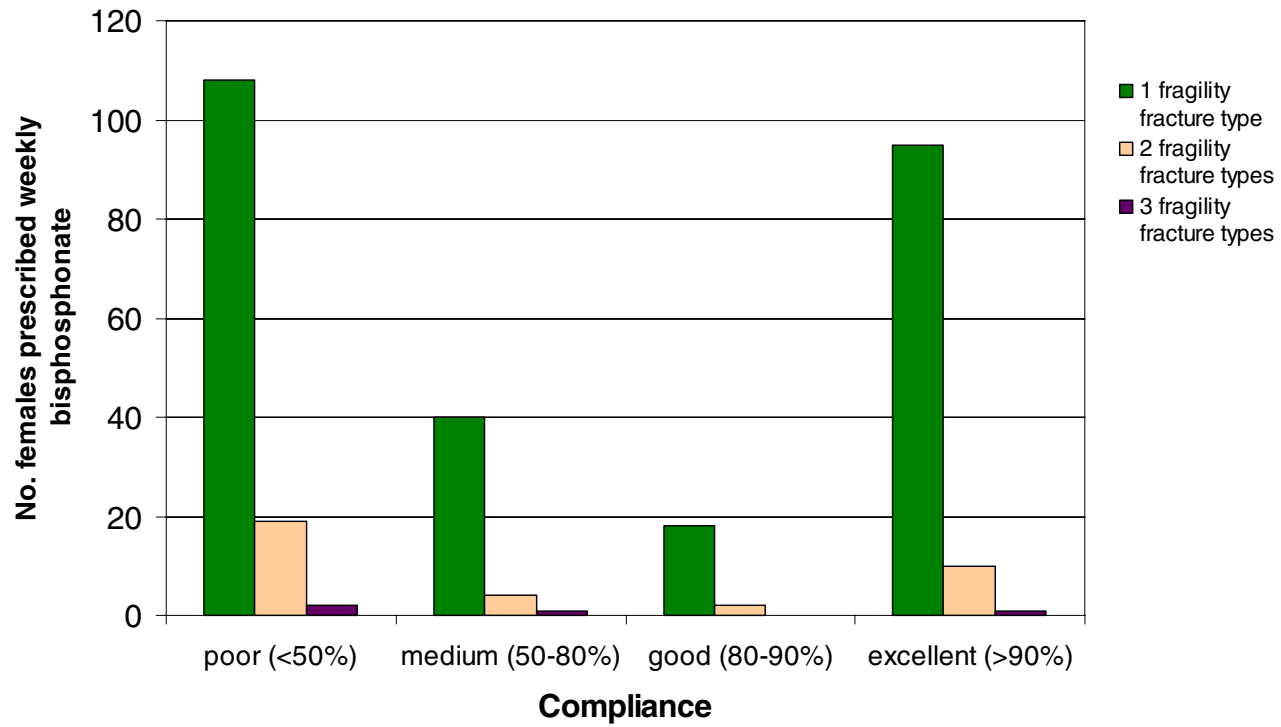


enter negative numbers-making any recording of "T-scores" impossible to interpret as they are all positive numbers [12, 14]. This method may have overestimated the level of compliance, as we cannot be certain that the medications prescribed were actually taken. We did not investigate HRT compliance because this therapy has a range of indications other than the treatment of osteoporosis.

\section{Comparison with the literature}

Poor compliance is a problem with many long-term medications and there is no single effective strategy to overcome this. Monitoring use of therapy, reminders to collect prescriptions and reducing the frequency of dosage have all been shown to be useful, but none provide the complete solution to this problem [24, 25]. Others have found similarly poor levels of compliance to bisphosphonate therapy [8]. Osteoporosis and occurrence of fractures are under-recorded compared to rates recorded in the literature [26-28] this is likely due to poor computer data quality $[12,14,17]$.

It is possible that including practices in a feedback loop will prove as effective in raising standards in this area as we have found in heart disease [16].

\section{Call for further research}

Studies are needed to develop interventions that result in improvements in data quality and the quality of care in osteoporosis. Further studies, with more complete datasets, are needed to evaluate whether there truly are differences in compliance between the different bisphosphonates.

\section{Conclusions}

Whilst computer searches will not identify everyone who might benefit from bisphosphonate therapy, they enable a start to be made on identifying a high risk population and implementing national guidelines. A pragmatic place to start improving the quality of osteoporosis management would be to utilise existing information technology to find non-compliant patients; especially those who have pre-existing fractures.

Acknowledgements Thanks to all the participating practices. This study was funded by an educational grant from Roche pharmaceuticals makers of ibandronate a treatment for osteoporosis. This paper is entirely the responsibility of the authors and has not been subject to editorial scrutiny by Roche.

\section{References}

1. Black DM, Cummings SR, Karpf DB, Cauley JA, Thompson DE, Nevitt MC, Bauer DC, Genant HK, Haskell WL, Marcus R, Ott SM, Torner JC, Quandt SA, Reiss TF, Ensrud KE (1996)
Randomised trial of effect of alendronate on risk of fracture in women with existing vertebral fractures. Fracture Intervention Trial Research Group. Lancet 348(9041):1535-1541

2. Harris ST, Watts NB, Genant HK, McKeever CD, Hangartner T, Keller M, Chesnut CH 3rd, Brown J, Eriksen EF, Hoseyni MS, Axelrod DW, Miller PD (1999) Effects of risedronate treatment on vertebral and nonvertebral fractures in women with postmenopausal osteoporosis: a randomised controlled trial. Vertebral Efficacy With Risedronate Therapy (VERT) Study Group. JAMA 282(14):1344-1352

3. Delmas PD, Ensrud KE, Adachi JD, Harper KD, Sarkar S, Gennari C, Reginster JY, Pols HA, Recker RR, Harris ST, Wu W, Genant HK, Black DM, Eastell R (2002) Mulitple Outcomes of Raloxifene Evaluation Investigators. Efficacy of raloxifene on vertebral fracture risk reduction in postmenopausal women with osteoporosis: four-year results from a randomised clinical trial. J Clin Endocrinol Metab 87(8):3609-3617

4. Chesnut CH 3rd, Skag A, Christiansen C, Recker R, Stakkestad JA, Hoiseth A, Felsenberg D, Huss H, Gilbride J, Schimmer RC, Delmas PD (2004) Oral Ibandronate Osteoporosis Vertebral Fracture Trial in North America and Europe (BONE). Effects of oral ibandronate administered daily or intermittently on fracture risk in postmenopausal osteoporosis. J Bone Miner Res 19(8):1241-1249

5. Recker RR, Gallagher R, MacCosbe PE (2005) Effect of dosing frequency on bisphosphonate medication adherence in a large longitudinal cohort of women. Mayo Clin Proc 80(7):856-861

6. McCombs JS, Thiebaud P, McLaughlin-Miley C, Shi J (2004) Compliance with drug therapies for the treatment and prevention of osteoporosis. Maturitas 48(3):271-287

7. Johnell O, Kanis JA, Oden A, Johansson H, De Laet C, Delmas P, Eisman JA, Fujiwara S, Kroger H, Mellstrom D, Meunier PJ, Melton LJ 3rd, O’Neill T, Pols H, Reeve J, Silman A, Tenenhouse A (2005) Predictive value of BMD for hip and other fractures. J Bone Miner Res 20(7):1185-1194

8. Caro JJ, Ishak KJ, Huybrechts KF, Raggio G, Naujoks C (2004) The impact of compliance with osteoporosis therapy on fracture rates in actual practice. Osteoporos Int 15(12):1003-1008

9. Pols HA, Felsenberg D, Hanley DA, Stepan J, Munoz-Torres M, Wilkin TJ, Qin-sheng G, Galich AM, Vandormael K, Yates AJ, Stych B (1999) Multinational, placebo-controlled, randomised trial of the effects of alendronate on bone density and fracture risk in postmenopausal women with low bone mass: results of the FOSIT study. Foxamax International Trial Study Group. Osteoporos Int 9(5):461-468

10. Huybrechts KF, Ishak KJ, Caro JJ (2005) Assessment of compliance with osteoporosis treatment and its consequences in a managed care population. Bone Dec 1 [Epub ahead of print]

11. National Institute for Clinical Excellence (NICE) Bisphosphonates (alendronate, etidronate, risedronate), selective oestrogen receptor modulators (raloxifene) and parathyroid hormone (teriparatide) for the secondary prevention of osteoporotic fragility fractures in postmenopausal women. London; NICE Technology Appraisal 87, 2005

12. de Lusignan $\mathrm{S}$, Chan $\mathrm{T}$, Wood $\mathrm{O}$, Hague $\mathrm{N}$, Valentin $\mathrm{T}$, Van Vlymen J (2005) Quality and variability of osteoporosis data in general practice computer records: implications for disease registers. Public Health. 119(9):771-780

13. Mitchell E, Sullivan F (2001) A descriptive feast but an evaluative famine: systematic review of published articles on primary care computing during 1980-1997. BMJ 322(7281):279-282

14. de Lusignan S, Valentin T, Chan T, Hague N, Wood O, van Vlymen J, Dhoul N (2004) Problems with primary care data quality: osteoporosis as an exemplar. Inform Prim Care 12(3):147-156

15. de Lusignan S, Chan T, Stevens P, O’Donoghue D, Hague N, Dzregah B, Van Vlymen J, Walker M, Hilton S (2005) Identifying patients with chronic kidney disease from general practice computer records. Fam Pract 22(3):234-241 
16. de Lusignan S, Hague N, Brown A, Majeed A (2004) An educational intervention to improve data recording in the management of ischaemic heart disease in primary care. J Public Health (Oxf) 26(1):34-37

17. de Lusignan S, Chan T, Wells S, Cooper A, Harvey M, Brew S, Wright M (2003) Can patients with osteoporosis, who should benefit from implementation of the national service framework for older people, be identified from general practice computer records? A pilot study that illustrates the variability of computerised medical records and problems with searching them. Public Health 117(6):438-445

18. van Vlymen J, de Lusignan S, Hague N, Chan T, Dzregah B (2005) Ensuring the Quality of Aggregated General Practice Data: Lessons from the Primary Care Data Quality Programme (PCDQ). Stud Health Technol Inform 116:1010-1015

19. van Vlymen J, de Lusignan S. A system of metadata to control the process of query, aggregating, cleaning and analysing large datasets of primary care data. Accepted for publication. Informatics in Primary Care September 2005

20. Clinical Information Consultancy. MIQUEST (Morbidity Information Query and Export Syntax). URL: http://www.clininfo.co. $\mathrm{uk} / \mathrm{main} / \mathrm{miquest.htm}$

21. NHS Public Health Network. Directly age-standardised rates. Downloaded from: http://www.avon.nhs.uk/phnet/methods/directly_age_standardised_rates.htm. Accessed 3rd July 2005
22. National Statistics. Population Trends 2003; 113 (Autumn): 45 (Table 1.4). Downloaded from: http://www.statistics.gov.uk/down loads/theme population/PT113.pdf. Accessed 3rd July 2005

23. Sanders KM, Nicholson GC, Watts JJ, Pasco JA, Henry MJ, Kotowicz MA, Seeman E (2006) Half the burden of fragility fractures in the community occur in women without osteoporosis. When is fracture prevention cost-effective? Bone 38(5):694-700

24. Krueger KP, Felkey BG, Berger BA (2003) Improving adherence and persistence: a review and assessment of interventions and description of steps toward a national adherence initiative. J Am Pharm Assoc 43(6):668-678

25. Richter A, Anton SE, Koch P, Dennett SL (2003) The impact of reducing dose frequency on health outcomes. Clin Ther 25 (8):2307-2335

26. Cummings SR, Melton LJ (2002) Epidemiology and outcomes of osteoporotic fractures. Lancet 359(9319):1761-1767

27. Holt G, Khaw KT, Reid DM, Compston JE, Bhalla A, Woolf AD, Crabtree NJ, Dalzell N, Wardley-Smith B, Lunt M, Reeve J (2002) Prevalence of osteoporotic bone mineral density at the hip in Britain differs substantially from the US over 50 years of age: implications for clinical densitometry. $\mathrm{Br} \mathrm{J}$ Radiol 75 (897):736-742

28. Vik SA, Maxwell CJ, Hanley DA (2005) Treatment of osteoporosis in an older home care population. BMC Musculoskelet Disord 6(1):7 